\title{
Tyrosine Kinase Inhibitors against Cancer: Their Safety in 216 Moroccan Patients
}

\author{
Lamyae Nouiakh*, Karima Oualla, Imane Ouafki, Soumia Berrad, Hayat Erraichi, \\ Lamiae Amaadour, Zineb Benbrahim, Samia Arifi, Nawfel Mellas
}

Department of Medical Oncology, Hassan II University Hospital, Fes, Morocco

Email: *nouiakhlamyae@gmail.com

How to cite this paper: Nouiakh, L., Oualla, K., Ouafki, I., Berrad, S., Erraichi, H., Amaadour, L., Benbrahim, Z., Arifi, S. and Mellas, N. (2021) Tyrosine Kinase Inhibitors against Cancer: Their Safety in 216 Moroccan Patients. Journal of Cancer Therapy, 12, 116-126.

https://doi.org/10.4236/jct.2021.123013

Received: January 7, 2021

Accepted: March 9, 2021

Published: March 12, 2021

Copyright $\odot 2021$ by author(s) and Scientific Research Publishing Inc. This work is licensed under the Creative Commons Attribution International License (CC BY 4.0).

http://creativecommons.org/licenses/by/4.0/

\begin{abstract}
Tyrosine kinase inhibitors (TKIs) have become a prominent option in the therapeutic arsenal of several cancers. The safety of these drugs has shown various toxicities with varying frequency and severity between different agents. The aim of this study is to describe the safety profile of different classes of TKI used in various solid tumors. It is a retrospectively descriptive study conducted in the Department of Medical Oncology at Hassan II University Hospital of Fez, Morocco, over a period of 6 years from April 2013 until April 2019. It included 216 patients who received one or more TKI for different indications in solid tumors. The average age in our series was 61.4 years with a sex ratio F/M of 1.07. Among the most used TKIs in our department according to their availability: Imatinib (32\%) and sunitinib (32\%). All patients received one or more tyrosine kinase inhibitors according to the indication. Kidney cancer was the most common malignancy (36\%), followed by gastrointestinal stromal tumors (33\%). The median duration of treatment was 15 months with extremes of 1 month and 102 months. The main side effects were: Cutaneous in $43 \%$ of patients. Digestive toxicity occurred in $36 \%$ of cases. Hematotoxicity was reported in $33 \%$ of cases. The safety profile of TKIs used in our study was comparable to their global tolerance reported in literature. More studies are needed to investigate the relationship between their toxicity and their efficacy in Moroccan population.
\end{abstract}

\section{Keywords}

Tyrosine Kinase Inhibitors, Safety, Side Effects

\section{Background}

Since 1998, new drug therapies have been discovered. Their mode of action mainly relates to the transduction of cell proliferation signals. Among these 
therapies, we find tyrosine kinase inhibitors.

Tyrosine kinase inhibitors (TKIs) represent an important therapeutic class in the management of patients with solid tumors. TKIs are small molecules of the quinazoline family that will diffuse across the cell membrane by targeting the signal transduction process at receptor tyrosine kinase [1]. TKIs are subdivided into several classes depending on the type of TK targeted: TKIs that target the EGFR pathway such as Gefitinib, Erlotinib, Lapatinib and Afatinib, TKIs that target the c-KIT pathway (Imatinib, Sunitinib) and TKIs of the VEGFR pathway (Sorafenib, Sunitinib, Axitinib, Pazopanib, Vandetanib, Regorafenib, Tivozanib, Vatalanib). TKIs bind to the ATP binding sites of receptor tyrosine kinases and block their activation. Consequently, the proliferation of cancer cells is inhibited [2].

These molecules are used especially in advanced or metastatic forms of cancer. Several studies have proven their effectiveness in terms of survival compared to conventional chemotherapy [1]. Most TKIs have a denomination ending with the suffix "IB". They work by competitively binding to the ATP binding sites of receptor tyrosine kinase. However, despite a specific intracellular mechanism of action, these agents are not immune to the problem of tolerance [3], because, they can be the source of several adverse effects. Tolerance of TKI may be influenced by the existence of comorbidities. There is great inter-individual variability in the occurrence of adverse effects, the mechanisms of which are still poorly understood.

The aim of this study is to describe the main adverse effects induced by TKIs of different classes, used for the treatment of solid tumors in our population and to compare our results with those reported in the literature.

\section{Methods}

\subsection{Type of the Study}

This is a descriptive retrospective study carried out in the medical oncology service of the Hassan II University Hospital in Fez, Morocco, over a period of 6 years from April 2013 to April 2019 in 216 patients.

\subsection{Study Population}

The inclusion criteria were: people over 18 years old, with a solid malignant tumor confirmed by histology, treated with one of the following TKIs: Sunitinib, Pazopanib, Sorafenib, Axitinib, Erlotinib, Afatinib, Imatinib and Regorafenib for different indications in solid tumors.

Epidemiological, clinical and therapeutic data as well as the safety profile were collected from medical files in their computerized form (available in the hosix software) or through files archived in the medical oncology department.

The various pieces of informations were listed in an exploitation sheet, established after bibliographic research and literature review.

Statistical analysis is done by SPSS version 23 software, qualitative variables 
are expressed as frequency and percentage and quantitative variables are expressed as median, mean and standard deviation.

\section{Results}

The mean age in our series was 61.4 years with age extremes ranging from 20 to 95 years. There was a slight female predominance (sex ratio F/M of 1.07). Among the TKIs most used in our service according to their availability: Imatinib (32\%), sunitinib (32\%), sorafenib (10\%), lapatinib (10\%), pazopanib (7\%), afatinib (5\%), erlotinib (2.5\%), regorafenib (1\%) and axitinib (0.5\%). All patients received one or more TKIs depending on the indication. Kidney cancer was the most common cancer (36\%) followed by gastrointestinal stromal tumors (33\%), breast cancer $(10 \%)$, non-small cell lung cancer $(7.5 \%)$, carcinoma thyroid (5.5\%), hepato-cellular carcinoma (4\%) and other tumors (4\%) (Table 1). The median duration of treatment was 15 months with extremes of 1 and 102 months. The main side effects were: cutaneous observed in $43 \%$ of patients; dominated by skin rash (under anti-EGFR: 50\% (grade 3 and 4: 22.5\%) (Figure 1), then hand-foot syndrome (on anti-VEGFR: 59.5\% (grade 3 and 4: 7\%)) then

Table 1. Patient characteristics.

\begin{tabular}{|c|c|c|}
\hline Characteristics & & Number (\%) \\
\hline \multirow{2}{*}{ Gender } & Male & $100(46)$ \\
\hline & Female & $116(54)$ \\
\hline \multirow{4}{*}{ Age } & $<40$ years & $24(11)$ \\
\hline & Between 40 and 60 years & $76(35)$ \\
\hline & Between 60 and 80 years & $108(50)$ \\
\hline & $>80$ years & $8(4 \%)$ \\
\hline \multirow{9}{*}{ TKI studied } & Imatinib & $69(32)$ \\
\hline & Sunitinib & $69(32)$ \\
\hline & Sorafenib & $22(10)$ \\
\hline & Lapatinib & $22(10)$ \\
\hline & Pazopanib & $15(7)$ \\
\hline & Afatinib & $11(5)$ \\
\hline & Erlotinib & $5(2.5)$ \\
\hline & Regorafenib & $2(1)$ \\
\hline & Axitinib & $1(0.5)$ \\
\hline \multirow{7}{*}{ TKI indications } & Kidney cancer & $78(36)$ \\
\hline & GIST & $71(33)$ \\
\hline & Breast cancer & $22(10)$ \\
\hline & Lung cancer & $16(7.5)$ \\
\hline & thyroidcarcinoma & $12(5.5)$ \\
\hline & $\mathrm{HCC}$ & $9(4.5)$ \\
\hline & Others & $8(4)$ \\
\hline
\end{tabular}


hair damage (alopecia: $65 \%$ on anti-VEGFR, hair depigmentation: $7 \%$ under suinitinib) (Figure 2 and Figure 3), and lastly, nail damage such as paronychia (anti-EGFR: 52.5\%) and sub-nail haemorrhages (anti-VEGFR: 43.7\%) (Figure 4). Digestive toxicity occurred in $36 \%$ of cases, it was in the form of diarrhea (on anti-EGFR: $62.5 \%$ (grade 3 and 4: 14.5\%)), nausea-vomiting (on anti-VEGFR: 34\% (grade 3 and 4: 5.5\%)) and stomatitis (anti-EGFR: 55\%, anti-VEGFR: 37.5\% (grade 3 and 4: $2 \%)$ ). Hematotoxicity was reported in 33\% of cases; anemia (anti-EGFR: $30 \%$ ) and thrombocytopenia (anti-EGFR: 20\%). Pulmonary toxicity occurred in only one patient who experienced hemoptysis on sorafenib.e Asthenia was observed with all three classes of ITK studied. Under antiangiogenic treatment; $10 \%$ hypothyroidism, $7.3 \%$ high blood pressure, and $1.3 \%$ proteinuria were noted, and no cases of thromboembolic complications were reported. No "fatal" adverse events were observed in our patients.

Table 2 summarizes the various adverse effects induced by TKIs in our study.

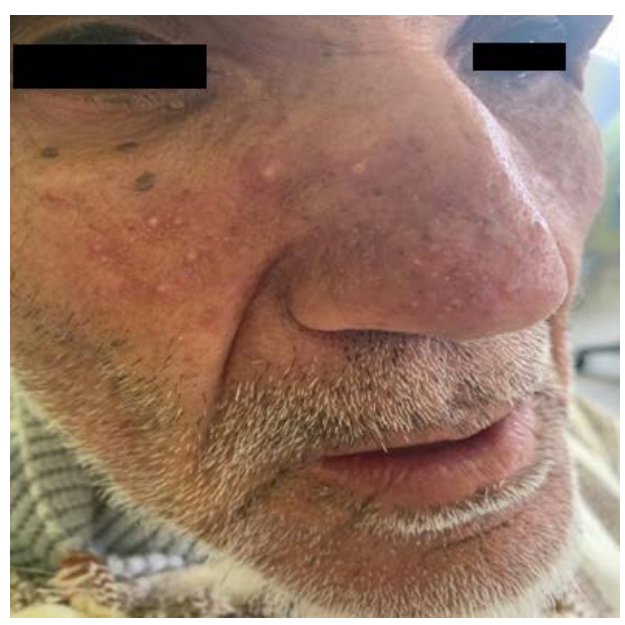

Figure 1. Skin rash under anti-EGFR (medical oncology service of CHU Hassan II in Fez, Morocco).

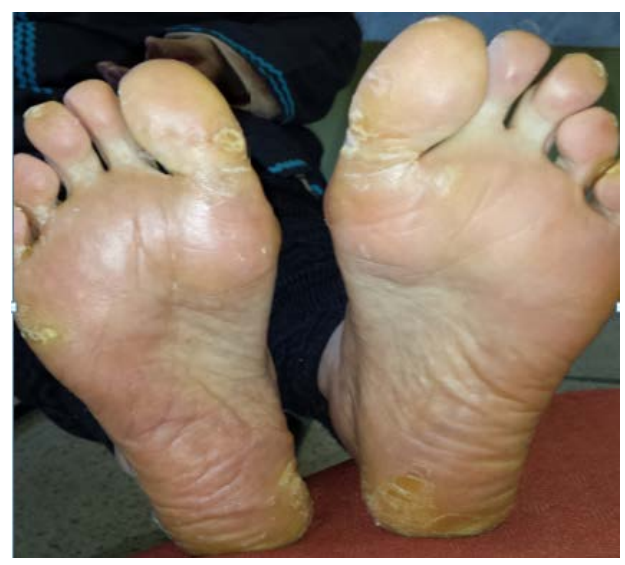

Figure 2. Hand-foot syndrome under anti-VEGFR (medical oncology service of $\mathrm{CHU}$ Hassan II in Fez, Morocco). 


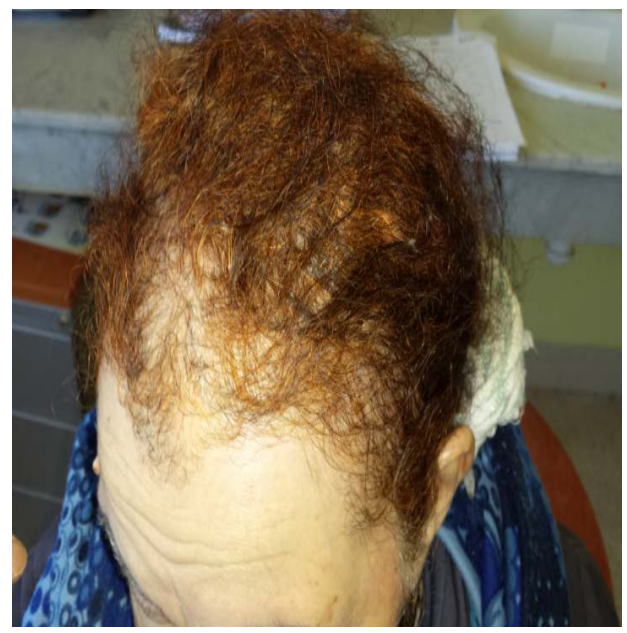

Figure 3. Hair depigmentation under sunitinib (medical oncology department of CHU Hassan II in Fez, Morocco).

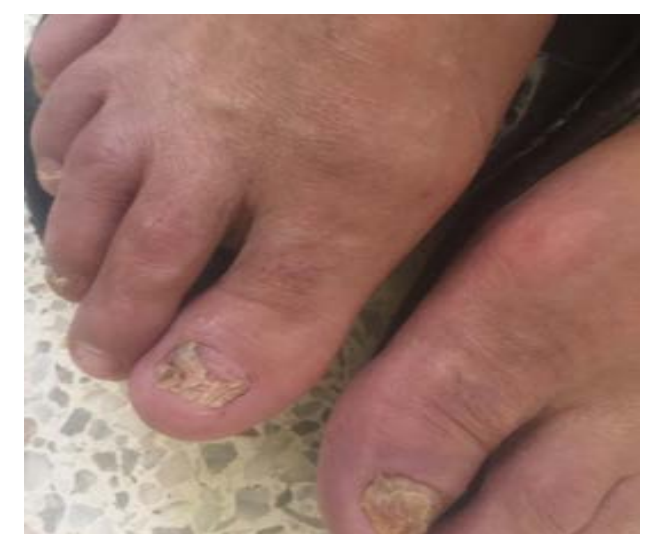

Figure 4. Paronychia under anti-EGFR (medical oncology department of CHU Hassan II in Fez, Morocco).

\section{Discussion}

The most common side effects with TKIs are: Skin involvement dominated by skin rash which represents the most frequent side effect, it is common to all targeted therapies studied with a different clinical presentation depending on the class of TKI received [4]. There are three types of rash: Acneiform rash, observed with anti-EGFR TKIs [5]; it is an acne-like rash, found in $45 \%$ to $100 \%$ of cases depending on the studies [6] [7]. In our series, it was observed in $50 \%$ of cases. It appears within eight to ten days of treatment starting, mainly affecting the face and upper trunk [4] [8]. The intensity of the skin rash correlates with the therapeutic response to anti-EGFR; the more severe the skin reaction, the better the response [6] [7] [8] [9], this can be explained by the better bioavailability of the product and the beneficial effect of the immune reaction in the tumor and also in the skin [9]. The second type of rash is seborrheic dermatitis, it concerns anti-VEGFR drugs, manifests itself clinically in the form of an erythema with 
Table 2. Main adverse effects induced by TKIs in our series.

\begin{tabular}{|c|c|c|}
\hline Sideeffects & TKI class/molecule & Percentage (\%) \\
\hline \multirow{3}{*}{$\begin{array}{l}\text { Skin involvement } \\
\text { Rash }\end{array}$} & Anti-EGFR & $27.5(\mathrm{G} 1, \mathrm{G} 2), 22.5(\mathrm{G} 3, \mathrm{G} 4)$ \\
\hline & Anti-VEGFR & $29.5(\mathrm{G} 1, \mathrm{G} 2)$ \\
\hline & c-Kitinhibitors(imatinib) & $11(\mathrm{G} 1, \mathrm{G} 2)$ \\
\hline \multirow{3}{*}{ Hand-foot syndrome } & Anti-EGFR & $17.5(\mathrm{G} 1, \mathrm{G} 2)$ \\
\hline & Anti-VEGFR & $52.5(\mathrm{G} 1, \mathrm{G} 2), 7(\mathrm{G} 3, \mathrm{G} 4)$ \\
\hline & c-Kitinhibitors(imatinib) & 0 \\
\hline \multirow{3}{*}{ Xerosis } & Anti-EGFR & $35(\mathrm{G} 1, \mathrm{G} 2)$ \\
\hline & Anti-VEGFR & $25(\mathrm{G} 1, \mathrm{G} 2)$ \\
\hline & c-Kitinhibitors(imatinib) & $17(\mathrm{G} 1, \mathrm{G} 2)$ \\
\hline \multirow{2}{*}{$\begin{array}{l}\text { Yellowish discoloration of the skin } \\
\text { Skin depigmentation }\end{array}$} & Sunitinib & 14 \\
\hline & Imatinib & 12.5 \\
\hline \multirow{3}{*}{$\begin{array}{l}\text { Hair damage } \\
\text { Alopecia }\end{array}$} & Anti-EGFR & 37.5 \\
\hline & Anti-VEGFR & 65 \\
\hline & c-Kitinhibitors(imatinib) & 35 \\
\hline \multirow{3}{*}{ Texture modification } & Anti-EGFR & 45 \\
\hline & Anti-VEGFR & 82 \\
\hline & c-Kitinhibitors(imatinib) & 0 \\
\hline Depigmentation & Sunitinib & 7 \\
\hline $\begin{array}{l}\text { Nailinvolvement } \\
\text { Paronychia }\end{array}$ & Anti-EGFR & 52.5 \\
\hline Subungualhaemorrhages & Anti-VEGFR & 43.7 \\
\hline \multirow{3}{*}{$\begin{array}{l}\text { Digestive damage } \\
\text { Diarrhea }\end{array}$} & Anti-EGFR & 47.5 (G1, G2), 15 (G3) \\
\hline & Anti-VEGFR & $32(\mathrm{G} 1, \mathrm{G} 2), 4.5(\mathrm{G} 3)$ \\
\hline & c-Kitinhibitors(imatinib) & 22 \\
\hline \multirow{3}{*}{ Nausea/vomiting } & Anti-EGFR & $37.5(\mathrm{G} 1, \mathrm{G} 2)$ \\
\hline & Anti-VEGFR & $28.5(\mathrm{G} 1, \mathrm{G} 2), 5.5(\mathrm{G} 3)$ \\
\hline & c-Kitinhibitors(imatinib) & $34.7(\mathrm{G} 1, \mathrm{G} 2)$ \\
\hline \multirow{3}{*}{ Stomatitis } & Anti-EGFR & $55(\mathrm{G} 1, \mathrm{G} 2)$ \\
\hline & Anti-VEGFR & $37.5(\mathrm{G} 1, \mathrm{G} 2), 2(\mathrm{G} 3, \mathrm{G} 4)$ \\
\hline & c-Kitinhibitors(imatinib) & $1.5(\mathrm{G} 1, \mathrm{G} 2)$ \\
\hline \multirow{3}{*}{$\begin{array}{l}\text { Hematologicinvolvement } \\
\text { Anemia }\end{array}$} & Anti-EGFR & $30(\mathrm{G} 1, \mathrm{G} 2)$ \\
\hline & Anti-VEGFR & $35(\mathrm{G} 1, \mathrm{G} 2), 1.8(\mathrm{G} 3, \mathrm{G} 4)$ \\
\hline & c-Kitinhibitors(imatinib) & $24(\mathrm{G} 1, \mathrm{G} 2), 2.7(\mathrm{G} 3, \mathrm{G} 4)$ \\
\hline \multirow{3}{*}{ Thrombocytopenia } & Anti-EGFR & $20(\mathrm{G} 1, \mathrm{G} 2)$ \\
\hline & Anti-VEGFR & $18(\mathrm{G} 1, \mathrm{G} 2), 4.5(\mathrm{G} 3, \mathrm{G} 4)$ \\
\hline & c-Kitinhibitors(imatinib) & $12.5(\mathrm{G} 1, \mathrm{G} 2)$ \\
\hline
\end{tabular}




\section{Continued}

\begin{tabular}{lll}
\hline & Anti-EGFR & 0 \\
Neutropenia & Anti-VEGFR & $3(\mathrm{G} 1, \mathrm{G} 2), 0.9(\mathrm{G} 3, \mathrm{G} 4)$ \\
& c-Kitinhibitors(imatinib) & $2.8(\mathrm{G} 1, \mathrm{G} 2)$ \\
\hline Asthenia & Anti-EGFR & $30(\mathrm{G} 1, \mathrm{G} 2)$ \\
& Anti-VEGFR & $41(\mathrm{G} 1, \mathrm{G} 2), 18.7(\mathrm{G} 3, \mathrm{G} 4)$ \\
\hline Others: & c-Kitinhibitors(imatinib) & $39(\mathrm{G} 1, \mathrm{G} 2)$ \\
\hline Edemas & Imatinib & 35 \\
\hline Hypothyroidism & Anti-VEGFR & 10 \\
Arterial hypertension & Anti-VEGFR & 7.3 \\
Proteinuria & Anti-VEGFR & 1.3 \\
Thrombosis & Anti-VEGFR & 0 \\
\hline
\end{tabular}

Legende: TKI: tyrosine kinase inhibitors, G1: grade 1, G2: grade 2, G3: grade 3, G4: grade 4.

desquamation, the topography of the lesions varies depending on the molecule administered, it occurs in the first weeks of treatment [10] [11]. The last type of rash is allergic rash, observed with c-Kit inhibitors such as imatinib, the clinical presentation is manifested in the form of itchy papules and macules involving the face, trunk, forearm and the legs [12] [13], as is the case in our study.

Another type of skin involvement can be seen with TKIs; it is the hand-foot syndrome: it is found especially with anti-angiogenic treatments, but it can be observed with anti-EGFR more particularly with lapatinib, but only within the framework of a combination of lapatinib and capecitabine [14]. Under anti-angiogenic treatment, this syndrome results in hyperkeratosis in the areas of friction, the evolution can be marked by the appearance of a bullous detachment or become inflammatory [10]. In the hand-foot syndrome seen with lapatinib, the clinical symptomatology is redness with edema [14]. Sometimes they can appear dander, ulcerations and bleeding. In our study, this syndrome was observed in 59.5\% under antiangiogenic therapy and in $17.5 \%$ under lapatinib.

Xerosis is another type of skin toxicity; observed with all TKIs. In our study, it was noted in $35 \%$ of cases under anti-EGFR treatment, $25 \%$ under anti-angiogenic drugs and in $17 \%$ under Imatinib. Our results were similar to those reported in the literature, xerosis affects one third of patients on anti-EGFR and anti-VEGFR after two to three months of treatment [9] [15], and it is clinically manifested by itching dryness, even painful with weakened skin [9] [16]. The yellowish discoloration of the skin is a toxicity associated with treatment with sunitinib. In our series, it was observed in around $14 \%$ of patients treated with sunitinib, this percentage can go up to $30 \%$ depending on the studies [10]. This coloration indicates an impregnation of the product but its presence and its intensity are not correlated with the effectiveness of the drug. Arriving at phanteric attacks; hair damage can be clinically manifested in three ways depending on the 
treatment received: alopecia, changes in texture and depigmentation of the hair. Beginning with alopecia, it has been found in the different classes of ITK studied with predominance in patients receiving anti-VEGFR. In the literature, it has been reported with anti-EGFR, anti-VEGFR and c-Kit inhibitors (imatinib) with a time to onset and a topography varying according to the treatment received [9]. On anti-EGFR, alopecia may develop two to three months after treatment starting. It concerns the vertex and the temporal gulfs mimicking androgenic alopecia [9]. On anti-VEGFR, alopecia is temporary with hair regrowth while continuing treatment [9] [10]. There are no data regarding the time to onset and the topography of it. Regarding changes in hair texture, they are seen mainly with anti-EGFR and anti-VEGFR treatments [15]. In our study, they were found in $82 \%$ and $45 \%$ of cases under anti-VEGFR and anti-EGFR respectively, the hair becomes fragile and dry. Hair depigmentation is a specific sign of sunitinib, which appears more or less late (four to six weeks after the initiation of treatment), it is characterized by alternating depigmentation and repigmentation of the hair, a "flag sign" [10] [17]; noted in 7\% of patients who received sunitinib in our study. About nail abnormalities; there are two types of attacks: Paronychia and subungual hemorrhages. Paronychia is found especially with anti-EGFR, they appear one to three months after the start of treatment [9], they are manifested by edema with erythema, sometimes they can appear as fleshy buds on the edges of the nails [4] [15]. In our series, they were present in $52.5 \%$ of cases under anti-EGFR. The second type of nail involvement is subungual hemorrhage; observed with anti-VEGFR in $43.7 \%$ in our study. They appear after the first four weeks of treatment as dark red or black longitudinal bands in the distal part of the nails [17].

Another type of toxicity associated with treatment with TKIs is gastrointestinal toxicity; found in $36 \%$ of cases in our series, it was in the form of stomatitis, diarrhea and nausea-vomiting. Beginning with diarrhea; this is an adverse reaction observed with all the targeted therapies studied in our series, were common in patients receiving anti-EGFR with a percentage of $62.5 \%$. According to the data in the literature, diarrhea appears in the first weeks after treatment and can be explained by a direct toxic effect of therapies targeted on the intestinal mucosa [18]. Stomatitis is observed mainly with anti-VEGFR and anti-EGFR, the clinical presentation is identical to the two therapeutic classes, they appear during the first two months [11]. In our series, they were noted in 55\% and 39.5\% under anti-EGFR and anti-VEGFR respectively. With regard to nausea and vomiting; generally, targeted therapies are weakly emetic [19], this emetizing potential may increase in the presence of risk factors (age less than 50 years, female sex, presence of anxiety, poor vomiting control during previous chemotherapy) [19]. Other side effects can be seen with TKIs, such as bone marrow suppression; it is observed especially with antiangiogenics and with c-Kit inhibitors, it is generally of low to moderate grade, rarely of severe grade [11] [20]. It occurs in the first months of treatment with imatinib [20], and in the third, fourth week of 
treatment with antiangiogenics [11]. Edema has been observed with imatinib; noted in $35 \%$ of patients receiving imatinib in our series. They most often occur in the lower limbs and periorbital. According to the literature, this percentage can go up to $60 \%$ [21] [20]. Arterial hypertension is a frequent sign under anti-VEGFR treatment, found in $5.3 \%$ in our series, this rate remains relatively low compared to that reported in the literature, this can be explained by the decline in treatment which was not enough important in our series because hypertension is a sign of late and slow onset [22] [23]. Its occurrence could be favored by the presence of the following factors (hypertension before initiation of treatment, presence of coronary artery disease, presence of renal cancer [24]). Hypothyroidism is a specific side effect of anti-angiogenic treatments; especially sunitinib [22], the correlation between hypothyroidism and treatment efficacy has been demonstrated in animal models, yet to be proven in humans.

\section{Conclusion}

Overall, the safety profile of the TKIs used in our study was comparable to that reported in the literature. Further studies are needed to study the relationship between their toxicity and their efficacy in the Moroccan population.

\section{Funding}

The authors received no specific funding for this study.

\section{Conflicts of Interest}

The authors declare that they have no competing interests.

\section{References}

[1] Boutayeb., S., Zakkouri, F.Z., Aitelhaj, M., Mesmoudi, M., Boutayeb, A., Boutayeb, W., Mrabti, H. and Errihan, H. (2012) Bilan des inhibiteurs de protéine tyrosine kinase dans le traitement des cancers. Pathologie Biologie, 60, 229-233. https://doi.org/10.1016/j.patbio.2012.05.007

[2] Merlin, J.L. (2008) Les inhibiteurs de tyrosine kinase en oncologie. La Lettre du Cancérologue, 17, 334-349.

[3] Gschwind, A., Fischer, O.M. and Ullrich, A. (2004) The Discovery of Receptor Tyrosine Kinases: Targets for Cancer Therapy. Nature Reviews Cancer, 4, 361-370. https://doi.org/10.1038/nrc1360

[4] Delamare, J., Delamare, F., Gélis-Malville, E. and Delamare, L. (2006) Dictionnaire illustré des termes de médecine. 29e Edition, Maloine, Paris.

[5] Gridelli, C., Maione, P., Amoroso, D., Baldori, M., Bearz, A., Bettoli, V., Cammilluzzi, E., Crino, L., De Marinis, F., Di Pietro, F.A., Grossi, F., Innocenzi, D., Micali, G., Piantedosi, F.V. and Scartozzi, M. (2008) Clinical Significance and Treatment of Skin Rash from Erlotinib in Non-Small Cell Lung Cancer Patients: Results of an Experts Panel Meeting. Critical Reviews in Oncology/Hematology, 66, 155-162. https://doi.org/10.1016/i.critrevonc.2007.10.004

[6] Morse, L. and Calarese, P. (2006) EGFR-Targeted Therapy and Related Skin Toxicity. Seminars in Oncology Nursing, 22, 152-162. 
https://doi.org/10.1016/j.soncn.2006.04.005

[7] Peréz-Soler, R. and Saltz, L. (2005) Cutaneous Adverse Effects with HER1 or EGFR Targeted Agents: Is There a Silver Lining? Journal of Clinical Oncology, 23, 5235-5246. https://doi.org/10.1200/JCO.2005.00.6916

[8] Robert, C. and Gimel, P. (2011) Management of Side Effects of Targeted Therapies in Renal Cancer: Cutaneous Side Effects. Bulletin du Cancer, 98, 35-46. https://doi.org/10.1684/bdc.2011.1448

[9] Bahleda, R., Besse, B., Barlesi, F., et al. (2008) Thérapies moléculaires ciblées en oncologie thoracique. John Libbey Eurotext, Paris.

[10] Autier, J., Mateus, C., Wechsler, J., Spatz, A. and Robert, C. (2008) Effets secondaires cutanés du sorafenib et du sunitinib. Annales de Dermatologie et de Vénéréologie, 135, 148-153. https://doi.org/10.1016/j.annder.2007.12.006

[11] Fléchon, A., Boyle, H. and Négrier, S. (2010) Gestion des toxicités des antiangiogéniques dans le traitement des cancers du rein. Bulletin du Cancer, 97, S73-S82. https://doi.org/10.1684/bdc.2010.1072

[12] Marin, D., Milojkovic, D., Bua, M., de Lavallade, H., Andreasson, C., Sauramba, P.R., Nicol, J., Gonzalez-Cinca, N., Goldman, J.M. and Apperley, J.F. (2007) The Use of Dasatinib in Chronic Myeloid Leukemia: Some Practical Considerations. Clinical Leukemia, 1, 229-233. https://doi.org/10.3816/CLK.2007.n.013

[13] Etienne, G., Milpied, B., Réa, D., Rigal-Huguet, F., Tulliez, M. and Nicolini, F.E. (2010) Recommandations du groupe Fi-LMC pour la gestion des effets indésirables du traitement par nilotinib (Tasigna ${ }^{\circ}$ ) au cours de la leucémie myéloïde chronique. Bulletin du Cancer, 97, 997-1009. https://doi.org/10.1684/bdc.2010.1136

[14] Conduite à tenir face à une diarrhée, un rash cutané ou une diminution de la fraction d'éjection ventriculaire gauche. Document du laboratoire GSK, Marly-le-roi Cedex.

[15] Dik, S.E. and Crawford, G.H. (2005) Managing Cutaneous Side Effects of Epidermal Growth Factor Receptor (HER1/EGFR) Inhibitors. Community Oncology, 2, 492-496. https://doi.org/10.1016/S1548-5315(11)70630-1

[16] Wu, P.A., Balagula, Y., Lacouture, M.E. and Anadkat, M.J. (2011) Prophylaxis and Treatment of Dermatologic Adverse Events from Epidermal Growth Factor Receptor Inhibitors. Current Opinion in Oncology, 23, 343-351. https://doi.org/10.1097/CCO.0b013e3283474063

[17] Robert, C. (2007) Cutaneous Side Effects of Anti-Antiangiogenic Agents. Bulletin du Cancer, 94, S260-S264.

[18] Loriot, Y., Perlemuter, G., Malka, D., Penault-Lorca, F., Boige, V., Deutsch, E., Massard, C., Armand, J.P. and Soria, J.C. (2008) Drug Insight: Gastrointestinal and Hepatic Adverse Effects of Molecular-Targeted Agents in Cancer Therapy. Nature Clinical Practice Oncology, 5, 268-278. https://doi.org/10.1038/ncponc1087

[19] Talbert, M., Willoquet, G. and Gervais, R. (2009) Le Guide Pharmaco Clinique. $1^{\mathrm{e}}$ Édition, Wolters Kluwer, Paris.

[20] Jabbour, E., Deininger, M. and Hochhaus, A. (2011) Management of Adverse Events Associated with Tyrosine Kinase Inhibitors in the Treatment of Chronic Myeloid Leukemia. Leukemia, 25, 201-210. https://doi.org/10.1038/leu.2010.215

[21] Guilhot, F. (2004) Indications for Imatinibmesylate Therapy and Clinical Management. The Oncologist, 9, 271-281. https://doi.org/10.1634/theoncologist.9-3-271

[22] Asmane, I., Barthélémy, P., Kim, S., Duclos, B., Bergerat, J.P. and Kurtz, J.E. (2008) Les effets secondaires des nouveaux traitements du cancer du rein. Médecine Théra- 
peutique, 14, 277-286.

[23] Halimi, J-M., Azizi, M., Bobrie, G., Bouché, O., Deray, G., des Guetz, G., Lecomte, T., Levy, B., Mourad, J.J., Nochy, D., Oudard, S., Rieu, P. and Sahali, D. (2008) Effets vasculaires et rénaux des médicaments anti-angiogéniques: Recommandations Françaises pour la pratique (SN, SFHTA, APNET, FFCD). Néphrologie \& Thérapeutique, 4, 602-615. https://doi.org/10.1016/j.nephro.2008.10.002

[24] Keefe, D., Bowen, J., Gibson, R., Tan, T., Okera, M. and Stringer, A. (2011) Noncardiac Vascular Toxicities of Vascular Endothelial Growth Factor Inhibitors in Advanced Cancer: A Review. The Oncologist, 16, 432-444.

https://doi.org/10.1634/theoncologist.2010-0271 